\title{
An Expanded Classification System of Linguistic Landscape and the Analysis of Dual Discourse Signage
}

Yi Li

Lecturer, School of Foreign Languages, Xinhua College of Sun Yat-sen University, Dongguan, Guangdong Province, P.R.China

Corresponding Author: Yi Li, E-mail: iliyi42@qq.com

\section{ARTICLE INFORMATION}

Received: November 19, 2020

Accepted: January 17, 2021

Volume: 4

Issue: 1

DOI: $10.32996 /$ ijllt.2021.4.1.16

\section{KEYWORDS}

Social media, Language learning, EFL students, Saudi Arabia

\section{ABSTRACT}

This paper is a 7-year-long empirical research carried out in China's southern cities of Guangzhou and Dongguan, with an aim to chart the unfamiliar "middle-ground" between the categories of public and private signage, which is inadequately discussed in conventional linguistic landscape studies. The paper offers substantial evidence to challenge the public and private or from-above and from-below dichotomy paradigm, and proposes a new category of "public-private dual discourse signage" in-between as a complement to the conventional categorization scheme. In the new system, two major types, namely mixing signage and hybrid signage are divided, and four subtypes are further elaborated, with samples discussed in detail. General background research and sociolinguistic studies such as geosemiotic and multimodal analysis are carried out to reveal the multiple driving forces behind the dual discourse signs. It is discovered that the signs' ownership structure and operation modes are crucial in explaining the complex phenomenon, longitudinal data draws distinctive trajectories and patterns for different subtypes of dual discourse signage. Furthermore, the practical implications and a possible shared future of harmony for the dual discourse signs is discussed.

\section{Introduction}

The semiotic landscapes of China may seem unfamiliar to the West and they could potentially provoke the re-examination of the relationship between signage and its geo-cultural circumstance, thus forcing the tourist to question the existing linguistic stereotypes of spatial practices and related theories, as Chmielewska (2010) put it, "When visiting a Chinese city for the first time, [...] Everything is new and noteworthy". But for a number of Chinese researchers, taking a stroll in the streets of Guangzhou, a cosmopolitan city in southern China, and placing the tourist gaze on the array of urban linguistic landscape is not an unfamiliar experience (Li, 2011; Wu \& Zhan, 2017). Abiding by the conventional theories and methodologies developed by Bourhis and Landry (1997), Scollon and Scollon (2003), previous Chinese linguistic landscape observations are fruitful in discovering the neologism of signs and the multilingualism that are distinctive in China, but are limiting in spotting some other features that might be more China-specific, and could potentially challenge the basic grounding of the existing linguistic landscape conventions.

\section{Literature Review}

The frequently cited dichotomy of signs, namely to distinguish them into 'private' and 'government' (Landry \& Bourhis, 1997) or 'top-down' and 'bottom-up' (Ben-Rafael et al, 2001), albeit not without question, seem to have been accepted and practiced widely in a large number of studies concerning semiotics in place. The former demarcation gives examples of private signs: commercial signs on storefronts and business institutions (e.g. retail stores and banks), commercial advertising on billboards, and advertising signs displayed in public transport and on private vehicle (Landry \& Bourhis, 1997); and of public (government) signs: public signs used by national, regional, or municipal governments in the following domains: road signs, place names, street names and inscriptions on state buildings including ministries, hospitals, universities, town halls, schools, metro stations, and public parks (ibid). Ben-Rafael et al (2001) followed this approach and went on further to subdivide the areas into a coding scheme containing sixteen variables, which has been applied by other researchers such as Cenoz and Gorter (2004). Although

K. C AL-KINDI CENTER R. D FOR RESEARCH ART Your gateway to world-class research

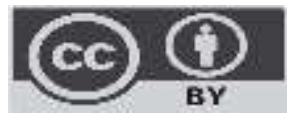

Published by Al-Kindi Center for Research and Development. Copyright (c) the author(s). This open access article is distributed under a Creative Commons Attribution (CC-BY) 4.0 license 
Blommaert (2013) did not follow this distinction but opts for a functional-oriented typology that consists of three broad categories that divide the signs by their 'lifespan', publicity signs and the commercial signs fall into different categories, with the former in 'Permanent signs', serving a landmark function, and the latter in 'Event-related signs', which have recruitment functions.

Figure 1: Conventional Semiotic Landscape Classification System

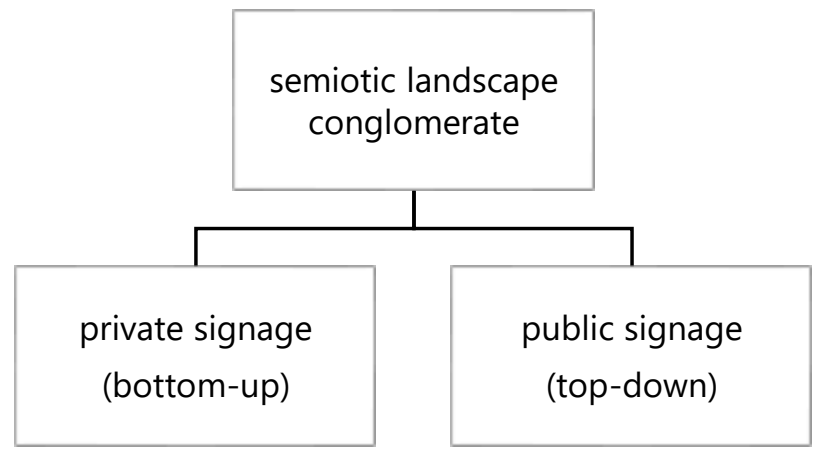

All the major private-public or public-private distinctions discussed appear to be clean cut and no 'middle ground' ever exists, as shown in Figure 1, thus it may offer a problematic starting point for researchers to decide their themes, whether it is to examine the status and power that are reflected in the official semiotic objects, or to explore the 'grass roots' identity and aspirations of its members as manifested in the private semiotic landscapes, or to analyze the power relations within the community when taking public and private signs together. Furthermore, these similar frameworks of division seem to assume that all the signs can be divided as prescribed, which in reality the process could turn out to be complicated, and the result conflicts the stereotypes.

\subsection{Inadequacy of the Dichotomy}

There have been arguments that confront such a public-private dichotomic division. Firstly, the underlying rivalry relationship might not be justified, Kallen (2010) has suggested that 'the contrast between 'top down' and 'bottom up' signages worked best on the assumption that these different types of signage were in opposition within the same system, representing different interlocutors vying for the same structural position in the landscape. This assumption, though, is contrary to a great deal of everyday experience: the state is not in the business of opening hairdressers or small shops, and small shop owners do not usually take to rebelling streets.' Kallen argued that street name signs and small shop signs were not directly competing, but lived in 'different, if parallel, universes'(ibid). Secondly, the 'from below' linguistic landscapes are prone to the influence of the government, since observations of commercial signs overshadowed by 'top down' policies are not rare, as Coupland (2010) discovered in his study of the Welsh linguistic landscapes, "what should count as linguistic landscaping 'from below' is less clear, partly because commercial initiatives (which Backhaus considers to be 'from below') have their own 'from above' qualities". In this regard, commercial signage voluntarily indexing non-profit environment messages could potentially be a real-life example suggesting the hypothesized private-public dual discourse sign.

In Dray's examination of Jamaican signage (Dray, 2010), a fast food KFC sign uses a slogan in the vernacular 'Nice Up Your City // Nice Up Yourself' to position itself as caring for a local community. Dray was careful enough to avoid using the term 'private', or 'bottom-up', but rather 'commercially-oriented signs', which leaf room for discussion as to what type of sign it was. The core image on this sign was commercial advertising, the peripheral 'Nice Up Your City' probably urged the viewer to behave themselves and keep the urban landscape nice and clean, which was indexical of a public service message usually initiated by the municipal government, though irrelevant the latter may seem, they were neatly designed and stay appropriately together on this one metal sign.

\subsection{Multiple Discourses within One Sign}

When Scollon \& Scollon studied the semiotic aggregate in the corner of Tat Chee Avenue and To Yuen Street in Hong Kong, they categorized the discourses in space into 15 types, which fall into 4 general categories: 1. regulatory discourses: municipal; 2. Infrastructural discourses: municipal; 3. commercial discourses; 4. transgressive discourses (Scollon \& Scollon, 2003). Once again, municipal and commercial discourses are clearly distinguished from each other. However, the Scollons claimed that this categorization did 'not make any clear distinction among discourses nor to determine exactly how many there might be, [...] they just want to demonstrate there are multiple, partly overlapping, but nevertheless distinct discourses operating within this semiotic aggregate' (2003). To deal with the complexity between genres of discourse, The Scollons went on to advocate the idea of 'interdiscursive dialogicality', which means 'several discourses co-exist simultaneously in a particular semiotic aggregate but 
none of the discourses is really internally altered by the presence of the other discourse. They operate quite independently semiotically'(2003).

The intriguing part is on what level the interdiscursive dialogicality can be valid, such as the case of the standalone KFC sign discussed above, where commercial discourse and public discourse co-exist within one sign, which is a much smaller unit than a semiotic aggregate that the Scollons defined as a particular place that is the result from the convergence, intentional or not, of multiple discourses (2003). Since the interdiscursive dialogicality gives the semiotic aggregate its most interesting characteristics but which is also most difficult to capture (ibid), it is similarly worthwhile to dig deeper into the interplay between different discourses within certain signs, which may give rise to a new category of signs in terms of semiotic discursivity, and shed light on some of the distinct features of semiotic landscapes in China and other 'exotic' places, see Figure 2 for a revised version of LL categorization scheme.

Figure 2: A revised semiotic landscape classification system

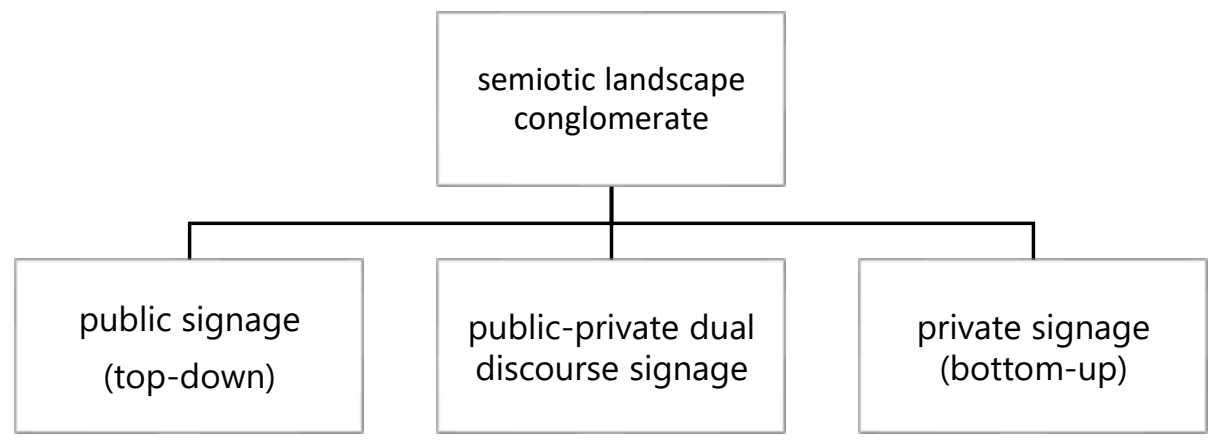

\section{An Expanded Classification System for Linguistic Landscape}

Before moving on to further discussions of the complexity behind the public-private dual discourse signage, amendments have to be made to the conventional public-private categorization scheme in light of the existing data. There are two issues have to be considered, firstly, the public and private discourses inscribed on the 'mixed' signage are usually not equal in geosemiotic terms, they tend to have a core and periphery relationship, with either public discourse being the main, commercial inscription being peripheral, or the other way round. Therefore, we can formulate a naming rule with the 'base type' of the sign, or the core discourse in the front, signaling its comparatively higher status than the peripheral element, which is placed in the latter, and a hyphen connecting the two connotating its discursive duality. For example, a "public-private sign" denotes a dual discursive sign whose core discourse is a public one, whereas a "private-public sign" means it's mainly a private sign but with some public elements. Theoretically, however, if the public and commercial discourses on a given sign are exactly on par in sociolinguistic terms, which seem to be a rare case, it is a public-private equal signage. therefore, there is still room for further discussion of completing this categorization scheme.

Secondly, we also have to differentiate "mixing" and "hybrid" signs. A "mixing" sign implies that there are no graphical or discursive boundaries between the private and public inscriptions within the border of one particular sign unit; either by design or layout, the two discourses seem to blend with each other in their artistic presence, like the cases of which we have studied in the previously part. For a "hybrid" sign, it's like a hybrid car that it can be driven by either fuel engine or electric motor, with clear distinctions, which means there are recognizable boundaries between public and private elements on a sign unit, either the hard edge of a physical sign plate or a box-layout on a printed screen that delineates two discourses on a giant billboard could be regarded as such a boundary. It should be noted that a "sign unit" may not be limited to a conventional signboard or sign plate, rather, it could include elements that are usually considered as one "sign" in the linguistic landscape dataset, for example, the aggregate of several sign plates on a sign post at a crossroad could be considered as a sign unit. Based on the ideas above and our dataset, public-private dual discourse signage can be categorized into 2 major types, with 4 specific subtypes in total, as shown in Figure 3, and the corresponding examples of subtypes are shown in Figure 4: 
Figure 3: An expanded semiotic landscape classification system
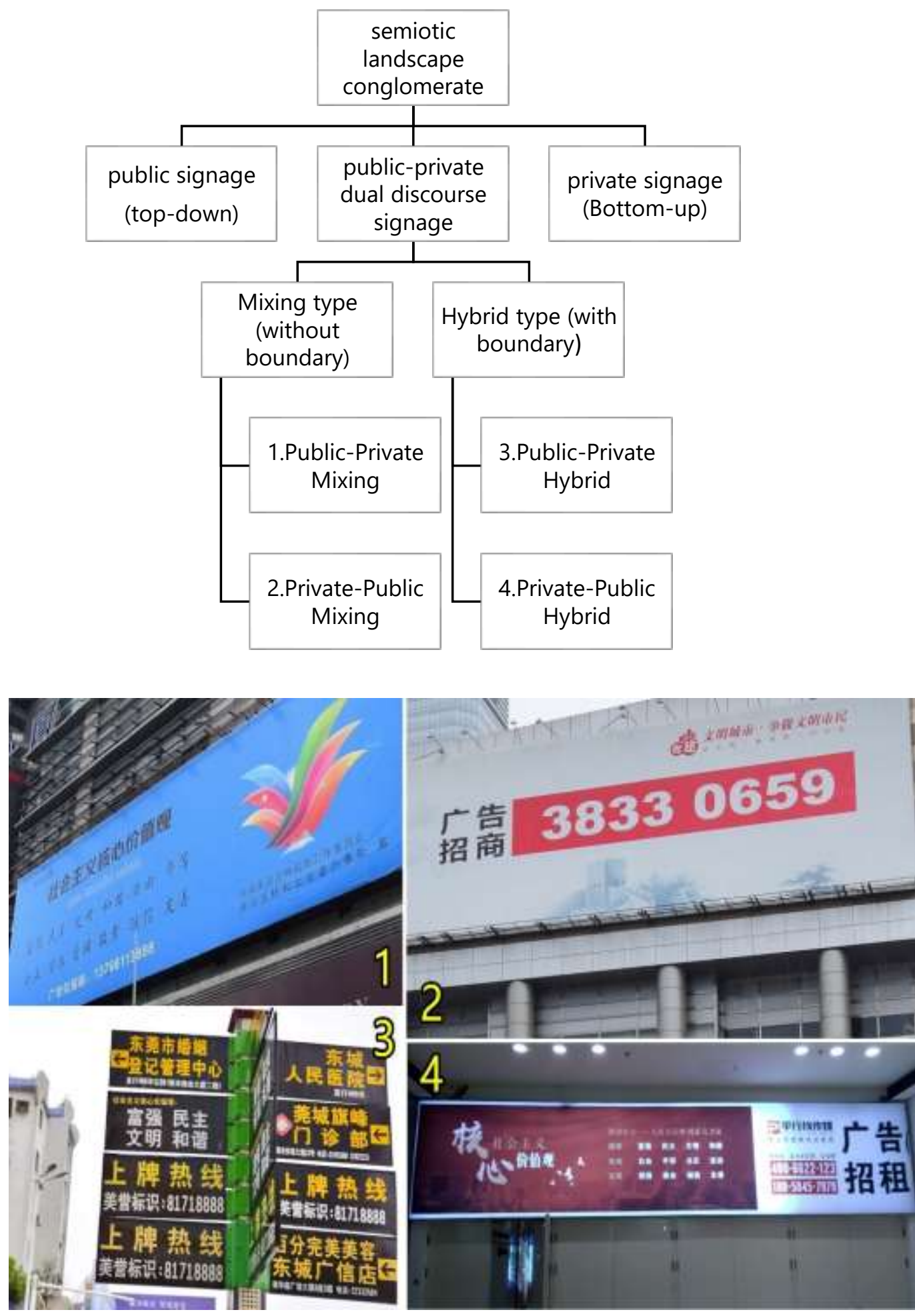

Figure 4. Examples of four subtypes of public-private dual discourse signage, with numbers corresponding to those in Figure 3. 


\subsection{Public-Private Mixing Signage}

Figure 5 is an enlarged version of quadrant \#1 in Figure 4, which is an example of public-private mixing sign. the preferred code / fonts are the Chinese public service messages, which are printed in larger fonts, taking a more central position, thus making them more prominent, or have a louder 'voice'. The background images or accompanying graphics also serve for this CORE public messages, which index the Chinese government's intention to advocate the public to participate in building a better community or achieving a better life. The producers of the public messages are political or government bodies, which are clearly inscribed, excluding any possible private 'authorship'. The peripheral code / fonts are the commercial text: Chinese 'Zhao Zu', or 'To Let' and the phone number(s), which are printed in smaller yet still recognizable fonts in the lower center position, announcing a moderate 'voice'. Although no graphics or images serve for this peripheral commercial message, with no relevant producer could be spotted, they index a particular group of commercial readers, who perhaps are among the readers of the public message, to attract their attentions to publicize their ads here or elsewhere.

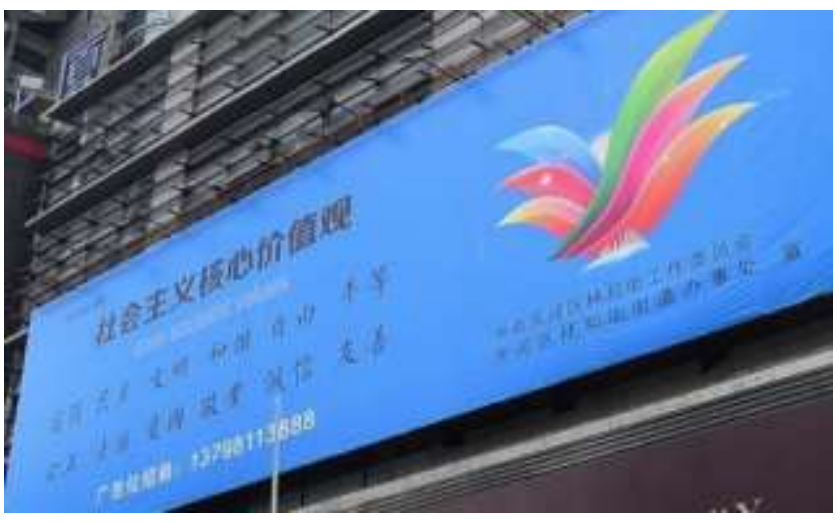

Figure 5. A public-private mixing sign, Guangzhou.

\subsection{Private-Public Mixing Signage}

We can also find examples of private-public mixing sign in Zhengjia Plaza, Tianhe District of Guangzhou, see Figure 6, a blowup of quadrant \#2 in Figure 4. It is a mixing sign because both public and commercial discourses share the same graphic background and color scheme with no clear boundaries. It is a private-prioritized mixing sign for the more prominent presence of commercial discourse takes up most of the sign area - four bold Chinese characters expressing an Ads space to-let message and a string of phone number sticking to its right. Public service announcement is subdued in small fonts, taking a little space at the upper right corner, promoting the civilized city campaign and urging the public to behave in a civilized manner. The ownership structure and operating mechanism behind the entire sign is similar to the public-private mixing sign we've discussed, despite its overtly louder commercial inclination, and also the "red sticker" design for the phone number offers a boundary, perhaps bringing a feeling of harmony between public and private discourses.

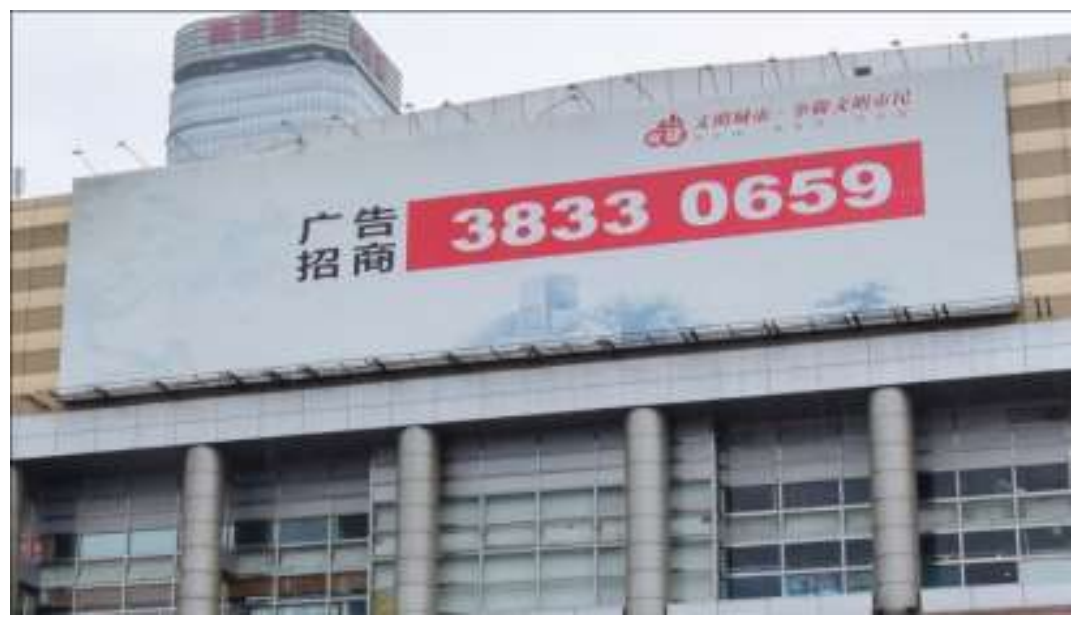

Figure 6. The giant private-public mixing sign on the top façade of Zhengjia Plaza, Guangzhou. 


\subsection{Public-Private Hybrid Signage}

For public-private hybrid signs, see the example in Figure 7 for an enlargement of quadrant \#3 in Figure 4. This is a street signpost which is considered as a single semiotic landscape unit on its own. Among the signboards being displayed on the signpost, the prominent signs are the public ones for the government and public non-profit institutions see \#1 in Figure 7. The second prominent is the paid-for place names, those installed right below the public signs are the ones showcase commercial institutions, which is placed in a lower than public, as exemplified by \#4 in Figure 7. The third type is the Public Service Advertisement (PSA), appear parallel to paid-for signs, announcing public service messages, \#2 in Figure 7 being the case. The last type is the Sign Maker's Self Advertisement (To-let), if not prominent, are the signs advertising the sign making companies per se, as shown by signboard \#3 in Figure 7.

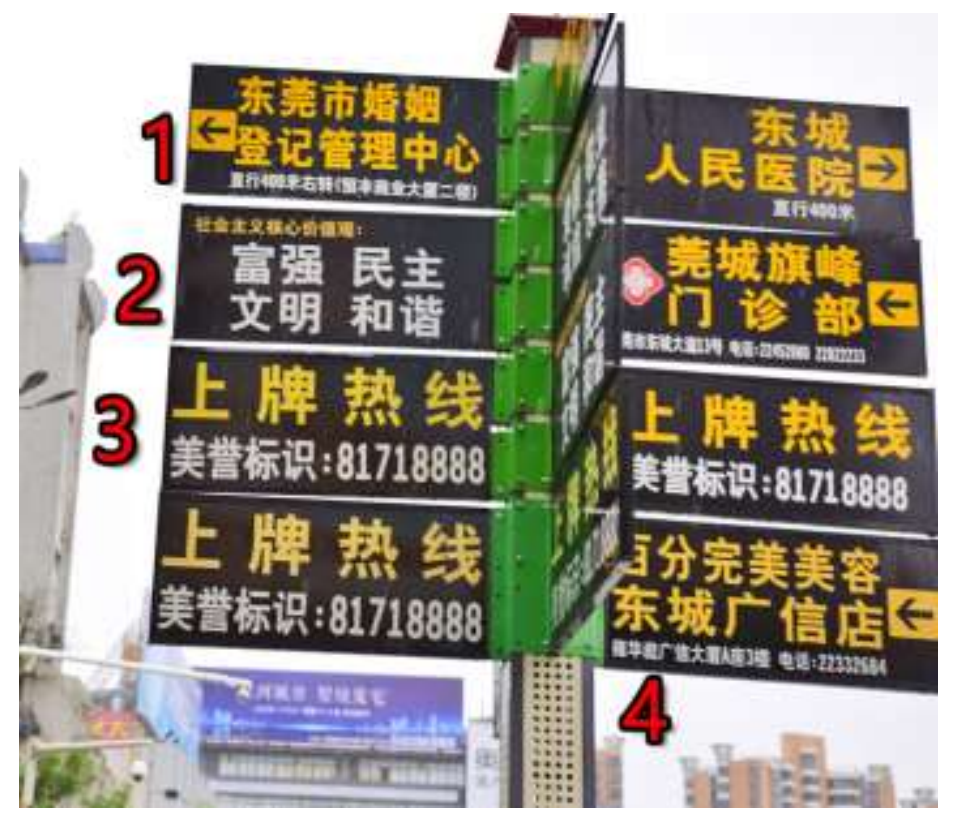

Figure 7. A public-private hybrid road sign in Dongguan city.

\subsection{Private-Public Hybrid Signage}

There are private-public hybrid signs found inside some of the large shopping malls. See Figure 8 , an enlarged version of quadrant \#4 in Figure 4, for a private-public hybrid sign. Its hybridity attributes to the clear boundaries that "box" the reddish public service announcement of core socialist values inside the brightly white Ad space to-let advertisement, again, with phone numbers. Even though the PSA takes up twice the space than that of the To-let Ad, it is still encircled by the latter's white framework, which denoting the commercial message is the main discourse on this sign.

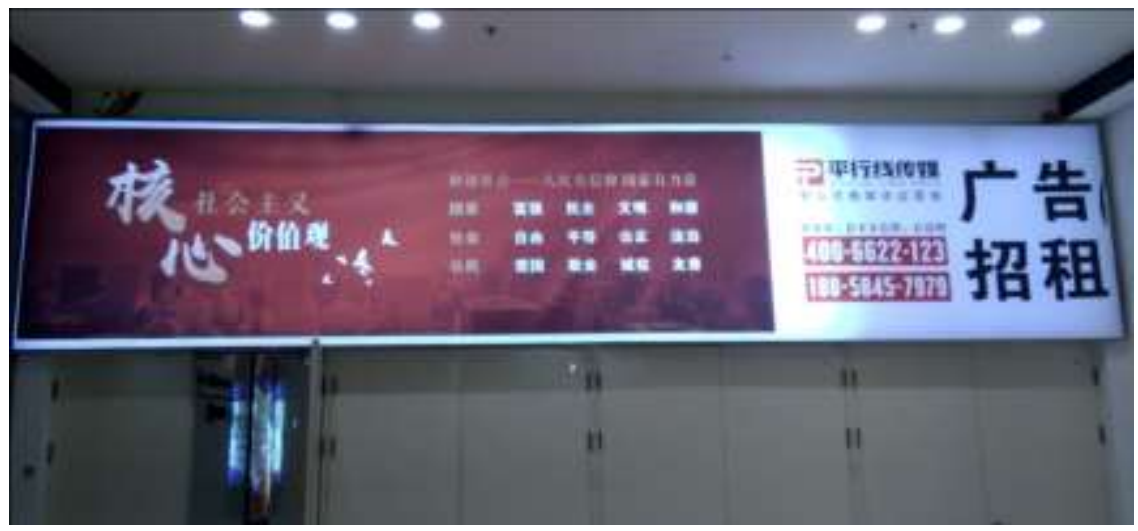

Figure 8. A private-public hybrid sign in Wanda Plaza, Guangzhou. 


\section{Public-Private Mixing Discourse: Rationale and Facts}

Among the researchers of semiotic landscape, there has been a favorable inclination towards the private sector, since the private ones usually appear to be more diverse, and reflect more accurately the multilingual reality of a particular area or location (Jaworski, 2010), by contrast, the government linguistic landscapes are regarded to be more monotonous within its formal boundaries, thus leaving less room for semiotic discussion. However, when a researcher is strolling in the traditional streets or modern avenues in Guangzhou, placing his/her tourist gaze around the urban semiotic aggregate, it is hard for him/her not to notice the existence of the oversized billboard screens around the lower part of buildings, and the small posters being posted on bus stops, public park fences and other communal places. The researcher might not comprehend what their contents are if they cannot read Chinese, but the similar, usually identical layout, styling, typography and color patterns that these screens and posters share would be an important clue to the reader: they are designed to be highly uniform in their presence, and their distribution are so widespread that in almost any given urban semiotic landscape, they are 'hard not to notice', if not ubiquitous. The uniformity across locations within the city, thus the 'decontextualized' characteristics of these signs, be it large screens or small posters, tend to make researchers lose interest because they carry an imprint of uniformed government signage, but they should not be overlooked. Since interesting semiotic hybridity phenomena are taking place.

\subsection{A Typical Case of Public-Private Mixing Signage}

Figure 5 is one typical example of the uniformed large screens posted on building walls; it is approximately $10 \times 3$ meters in size and mounted at about 6 meters above ground without visible framing. The layout follows a Chinese typographic convention, with main message on the left and 'signature' of the producer at the lower right corner, and a colorful plant-like graphic with Guangzhou characteristics is on the right to decorate the entire sign. To begin with, the producer use the 'We' strategy to involve the readers as insider by using 'Our values' as the form of address to open this public announcement, note the small fonts located at the very upper-left corner. However, tourists from the globe may immediately recognize the gray English words in the mid-right position --- 'core socialist values', which is juxtaposed by its Chinese equivalent above them, the nine larger, bold-type Chinese characters read 'She Hui Zhu Yi He Xin Jia Zhi Guan', below the English, is the content of such values, they are presented in Chinese only, with neat calligraphic typeface and even spacing.

These are well-thought-out notions, each with positive connotations, the first line from the left, namely, 'Prosperity, Democracy, Civility, Harmony, Freedom, Equality', and the second line from the left, 'Justice, the Rule of Law, Patrioticism, Dedication, Integrity, Friendship'. The two-line 'signature' part at the lower right, marking the initiators of this sign, the typography of which also follows a politically-inclined Chinese convention, the Communist Party comes first in the first line, and government comes after in the second line, Namely, in English, 'Communist Party of China (hereinafter referred to as CPC) Working Committee of Linhe Street, Tianhe District' for the first line, 'Linhe Subdistrict Office of Tianhe District', which is affiliated to the Guangzhou municipal government, in the second line.

So far, the analysis convinces us that the discourse on this large screen generally falls into a typical public service sign category, with rigid typography and articulated spacing, it conveys a message from the CPC and government to educate the general public about socialist values that 'we' Chinese people should all be familiar with, perhaps also put into practice. However, at the lower right, an 11-digit cellular phone number in bright white that stands out from the sign would not escape the tourist gaze, to its left, the Chinese meaning 'Advertising Space to Let', it is an entirely commercial discourse that is addressing to a different and particular audience who desires to put their Ads up here on the screen or somewhere else. Who produces this bit of information is unknown, could it be the CPC and government, or someone behind the phone number, or both? This short discourse in white seems to disrupt or even defy all those in black, the 'recruitment functions' of this number indexes a commercial participant reaching out to the potential clientele, if such a deal is made, could the public service message on this sign be overthrown and replaced by some commercial advertisement?

\subsection{Minimum Requirements on PSA Presence}

In order to find out the rationale behind the distinct public-private mixing phenomenon, we have to examine the spatial situatedness of the screen in Figure 5, which is shown in Figure 9, which illustrates a corner between Tianhe Lu and Wenhua Jie in Tianhe District, Guangzhou's new urban center. According to local regulations, this semiotic aggregate is located in one of the seven 'key landmark areas' in Guangzhou, which is also termed by the Guangzhou municipal government's advertising and billboard regulation (Guangzhou Municipal Government, 2006/2010/2014/2018) as the 'special control zones', where all forms of signage are subject to rigid scrutiny. It is worthwhile to note that the regulation briefly divides the billboards and signboards into two categories according to their nature of operation: public service advertisement (PSA) in the interest of the society, and commercial for-profit advertisement. And such division is introduced for requiring the number of the PSAs should not be less than $3 \%$ of the commercial ads (ibid.), but there is no upper limit for the PSAs. Another note-worthy point is that this 'Article 6' guaranteeing a minimum 3\% PSA presence had been removed in the 2010 version of the regulation and henceforth, the 2014 
and 2018 version. However, we can still find that the effects of such policy carry well into 2017, leaving a significant proportion of PSAs in landmark areas.

In Figure 9, on the building's left façade facing Tianhe Lu, on the same level of the blue Core Socialist Values screen, a whitish 'Save Water' screen further away is deployed symmetrically to it, in-between the two is the red-and-black signboard for 'Gome' Electronic Appliances Store, though its height is greater, but it is dwarfed in size by its adjacent PSAs. Below these three signs, there is another set of three signs on the ground floor level, their lengths and heights do not exceed those of the two PSAs and 'Gome' sign that we analysed earlier. In total, there are 6 signs on this building façade, 2 of them are public-private coexistent PSAs, accounting for roughly $33 \%$ of total signage, and $50 \%$ of the commercial signboards, that is way above the $3 \%$ minimum requirement for PSAs.

If separating the public and private hybrid inscriptions on each PSA into two respective public and private signs, the 2 purely public announcements still make up $25 \%$ of the total, and $33 \%$ of the commercial counterparts, the proportion is still well above the lowest limit that the government expects them to be. If regulatory factor is one driving force behind the installation of PSAs, it could not explain the skewed high proportion of them; or the overt presence of the commercial inscriptions on them. The ownership structure concerning the PSAs and commercial signs have to be taken into account.

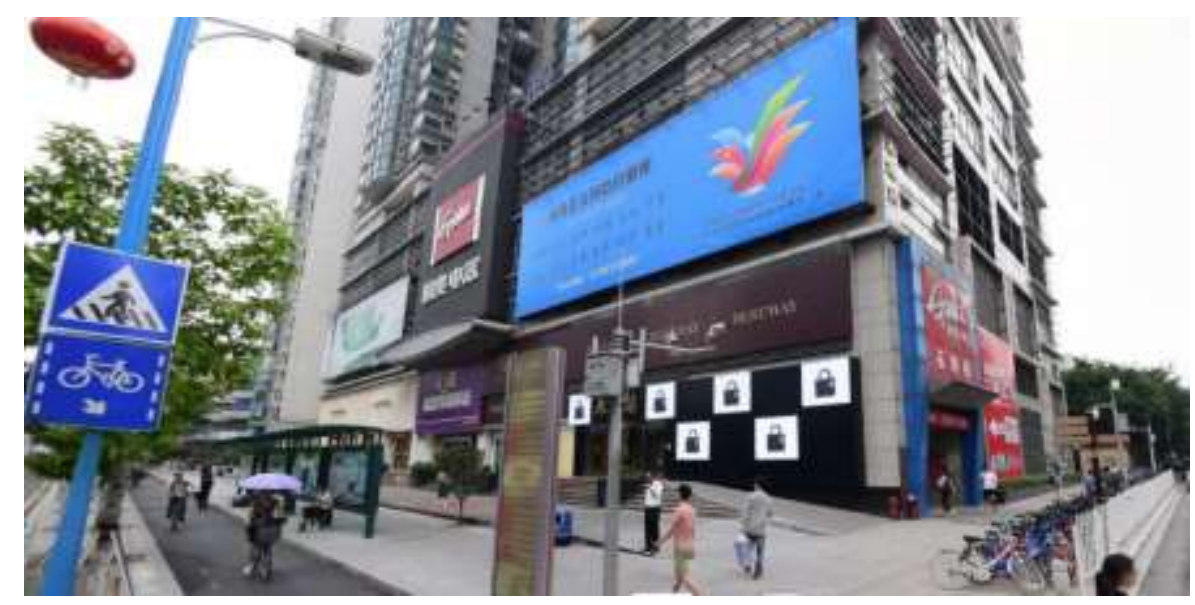

Figure 9. The semiotic aggregate of Figure 5, Guangzhou, 2017.

\subsection{Co-Ownership and Dual Identity}

In 2009, the Guangzhou municipal government issued a new regulation, which stipulated that any outdoor advertising space on private property has to be auctioned before going to market, the 'Chengguan' (Urban Management Administration) will be the only contracted party to act on behalf of the property owners in the auctions, through which the private ad space will be marketed and priced. In the end, $60 \%$ of the auction proceeds will go to the property owner and the rest $40 \%$ to the government. In 2009, Mr. Su Zequn, the then deputy Mayor of Guangzhou, explained to public about the rationale for the government to take a $40 \%$ share of advertising revenue:

Outdoor advertisements are different from other advertisements; their proper functioning depends utilizing public space in addition to the property where they are installed. For instance, a private advertising space is auctioned at 60 million Yuan, but if such a space does not abide by the rules of urban planning, the property owner cannot deploy the advertising legally, thus no ad revenue will be generated. In this regard, the property owner cannot be the sole recipient of the auction proceeds, which is an embodiment of the value generated through the combination of the property and public space. The public space belongs to the public. The government only obtains a proportion of the rights and interests in ad revenue on behalf of the public, and uses the money for projects in the public's interests. (Anonymous, 2013)

From the Mayor's statement, we can conclude that: 1. the Guangzhou municipal government holds jurisdiction over outdoor billboards and signboards, public and private, the related municipal administrative power is exercised in the form of formulating urban plans, which play a crucial role in designating advertisement areas, regulating their presence and setting up prohibited 
zones etc., an advertiser cannot bypass the government plans and publicize any advertising. 2 . The Guangzhou government is also entitled to $40 \%$ of the advertising revenue that each commercial billboard generates, making it the second largest beneficiary for each billboard, probably the sole largest recipient with the highest Ad earnings across the Guangzhou city, unrivalled by any single business entity.

This is an important message that could shed light on the public-private dual discourse screen phenomena; a tentative theory is that the compounding of the public-private discourses on the PSAs in public space is a result of the Government-Proprietor dual ownership of the outdoor billboards. And the co-ownership leads to the dual identity of the government, on the one hand, the government ('Chengguan') acts as the authority and uses its administrative and regulatory rights to sanction spaces for public and private advertising, and to design and install PSAs.

On the other hand, the authority also acts as a commercial participant, expecting to earn its share of the commercial ad revenues, as much as possible, probably. It's speculated that this dual identity of the government forces itself to perform two different roles, firstly formulating the public service announcement in the public's interests, and secondly, allowing property owners to put up 'To-Let' phone numbers to attract potential advertisers and earn revenues. From the estate proprietors' perspective, although their rights to the ad revenues appear to be 'encroached' or 'impaired' in the name of public interest, they might 'hitch a ride' in getting their to-let advertising spaces publicized by the government's PSA efforts, since there is no successful advertising business the estate owner can claim anyway.

However, if a deal is to be made between the estate owner and the advertiser payer, the PSA shall give way to a purely commercial billboard and the public-private mixing screen will be removed, as we've found in the year of 2020, at the same location, the left screen have been replaced by a traditional Chinese medicine healthcare clinic commercial, the right one is replaced by a real estate advertisement. The 'demise' of PSAs on this building façade is acceptable as long as the bottom-line of PSA's 3\% presence is guaranteed in the monitored business area.

\section{Public-Private Hybrid Signage - BOT Signposts and its Development}

In the previous part, we have analysed samples of stand alone public-private (or private-public) mixing and hybrid signage in Guangzhou, which were present in the form of large screens on a building façade or inside a shopping mall, giving public service announcement with advertising space to-let phone numbers. When we drove $90 \mathrm{kms}$ east, and looked at the crossroads in the eastern suburb of Guangzhou city as well as Dongguan city, we would the second major type, public-private hybrid signage, which in our dataset appears most evidently in the form of pedestrian signposts installed with public place names, public service announcements together with paid-for place names.

\subsection{BOT Signpost: Physical Configuration}

Figure 10 shows the general features of such a signpost: 1 . the signpost has only four vectors, any given vector is fixed perpendicular to another if looking directly downward from above. In other words, the vectors are fixed a crisscross fashion, namely 90 degrees, 180 degrees, 270 degrees and 360 degrees, which offer limited directional accuracy, given the fact that it is unlikely for the location of a signified party on each sign can be aligned with the fixed vectors.

Each vector has two sides for inscription, viewing from any given angle, only two sides on two respective vectors are visible, with the rest six sides being partially blocked or invisible, however, inscriptions on each vector are identical regardless of whether the 'front side' or the 'back side' they are on, so there are exclusive contents on only four sides of each post, but not eight sides. Therefore, we don't have to take four pictures from four angles to capture the entire signpost, but two pictures taken at a right angle would suffice.

3. Each vector can accommodate up to five signs in a row before 2015, but was later reduced to four after an upgrade campaign promoting to the 'large format' signs around the year 2016.

4. For each sign in black, the basic semiotic rule contains three elements: A. a name of the signified institution, presented in fluorescent yellow bold type Chinese characters; B. Beneath the name, a string of much smaller inscription in white, giving supplementary information, such as the address and/or phone number for the entity; $\mathrm{C}$. at the outward part of the sign beside the inscriptions, there is a yellow square, in which a larger black pointing arrow or detour arrow shows the signified institution's spatial location in relation to the post. 


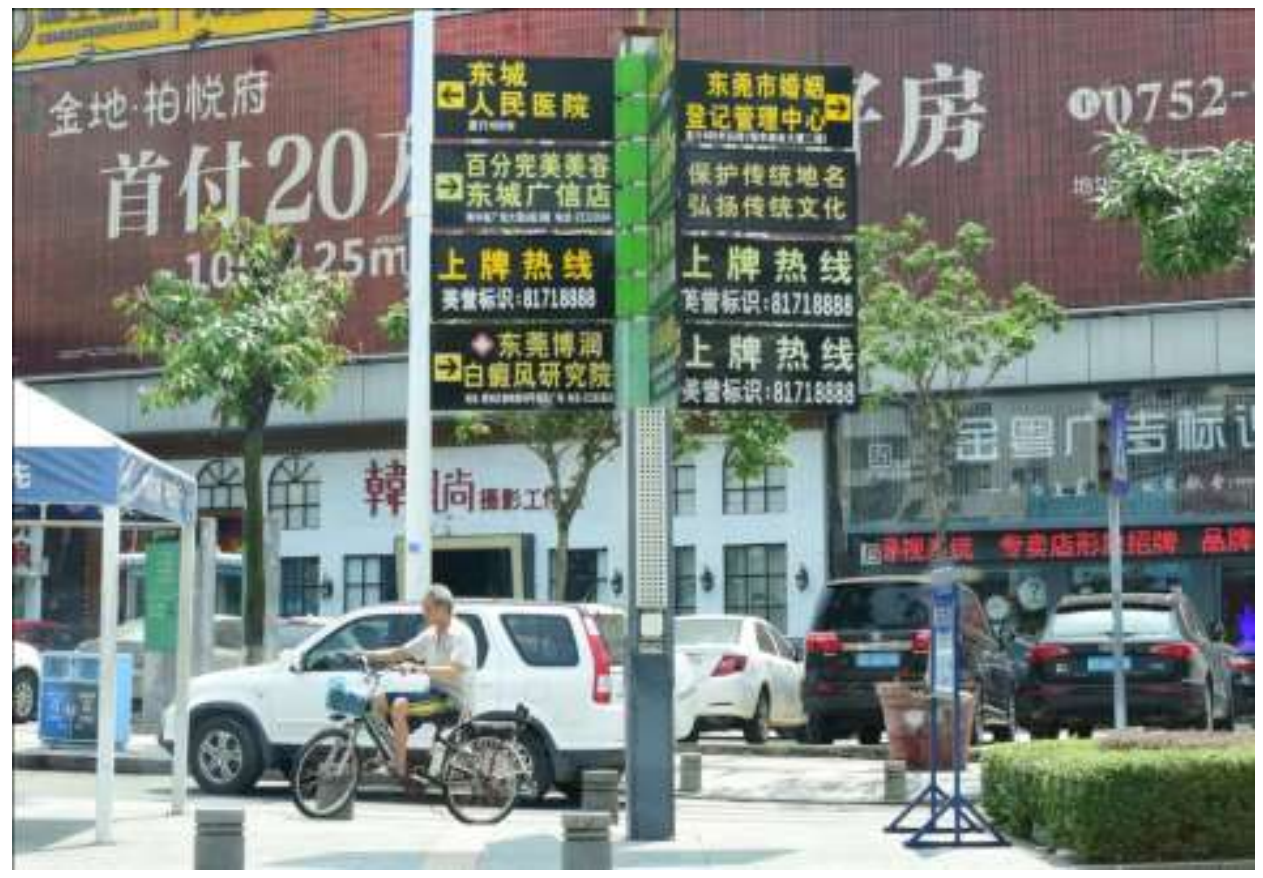

Figure 10. A pedestrian signpost at the crossroad of Nancheng Lu and Luosha Lu, observer looking south, Dongguan.

\subsection{BOT Signage: Discursive Multiplicity and its Categorization}

It is the 'noises' on this signpost that caught our attention. On the signpost in Figure 10, sign \#2 and sign \#4 on the left, which are supposedly pointing to the left by nature, but the arrows in the printed yellow boxes are pointing to the right, it is a case of semiotic markers defy the norms. Sign \#2 on the right appear to be a public service announcement (PSA) similar to the function of the core socialist values, to promote human goodness and discourage the otherwise; it is translated as "Protect traditional place names, promote traditional culture".

What is more interesting is the two signs directly below and one sign diagonally underneath the PSA, there are four yellow Chinese characters in obviously larger than usual font size, meaning "Listing Hotline", accompanying it on the bottom of the sign, is the 'Meiyu Signage' and phone numbers in white, it appears to be an advertisement for a signage manufacturer but nevertheless fixated on a public signpost. For these three signs, no arrows are present to point out any direction, nor any address to mark an institution if there is one. The 'decontextualized' nature of PSA signs and Sign maker's self-advertisement defies the public situatedness and the spatial guiding function of conventional pedestrian signposts, and begs for further investigations.

The legitimacy of the establishments displayed by the other signs on this signpost is also worthy of questioning, on the left vector, in a top-down order, the institutions are: \#1 Dongcheng People's Hospital, \#2 Baifen Wanmei Cosmetics Dongcheng Guangxin Clinic, \#3 Listing Hotline. \#4 Dongguan Borun Leucoderma Research Institute. And on the right vector, from top, the signified are: \#1 Dongguan City Marriage Registry Office, \#2 Public Service Announcement, \#3 Listing Hotline, \#4 Listing Hotline.

It's noticeable that the institutions labeled \#2 on the left vector and \#4 on the left are not publicly funded hospitals in the conventional sense, but rather for-profit private clinics for a specific audience, namely women who want cosmetics service and patients suffer from Leucoderma. It is speculated that these commercial institutions got their names, addresses and phone numbers 'listed' on the public signpost through a business deal with the sign maker 'Meiyu Signage'. Examining such signs across our database, in Scollon \& Scollon's geosemiotics' terms (2013), there are some of the similar semiosis process taking place on these public-private hybrid pedestrian signposts:

(1) The prominent signs are the Public ones for the government and public non-profit institutions, e.g. government offices, public schools and hospitals, etc., which are always placed on the highest positions of the post, taking a more visible position from a distance, thus making them have a louder 'voice'. They might index the government's authority and legitimacy over the signpost and reinstate the basic function of road signs.

(2) The second prominent is the paid-for place names, those installed right below the public signs are the ones showcase commercial institutions, which is placed in a lower than public, but perhaps more centric position, though their cannot be seen 
as long in a distance as the public type, they still announce a moderate 'voice'. They might index a vibrant local business community, a particular group of businesses who would like to 'sell' to the pedestrians who are interested in what they offer.

(3) The third type is the Public Service Advertisement (PSA), appear parallel to paid-for signs, announcing public service messages. Although they are ranked in such a way that the sign could be seen easily, but their number is limited. As another note, this type has not been found on similar signs in Zengcheng city.

(4) The last type is the Sign Maker's Self Advertisement (To-let), if not prominent, are the signs advertising the sign making companies per se. Although the fonts used are arguably the largest among other signs on the post, their ranking on the row are lower than the previous types, and they are addressing a smaller audience of eager-to-publicize businesses, thus they tend to be less attractive to or even considered redundant by the common pedestrians.

It is only a tentative attempt to categorize the multiple discourses into the four groups above, since using a single criteria, e.g. ranking position on a row, would not account for the complex dynamics when other competing factors come into play, e.g. font colors, sign sizes, etc. Therefore, similar to the analysis of the public-private mixing sign, we have to turn to investigate the ownership structure and working mechanism behind the semiosis, to reveal a clearer picture of 'what's going on' for such unconventional public-private hybrid signposts.

\subsection{Rationale for BOT Multiple Discourse Signage}

Through the official website Meiyu Homepage (http://www.meiyu88.com) of the sign maker 'Meiyu Sign', an important clue comes to surface, that is the BOT business model they adopted for this entire sign manufacturing activity. BOT stands for 'BuildOperate-Transfer', in which way Meiyu claims they are the first in China to commercialize the operation of public projects. With the sign ownership lies completely with the government and under authority's supervision, Meiyu's business seem to be endorsed officially and it also promises the designing, making and installing of signs does not 'cost a penny' from the taxpayers. The rationale behind this BOT mechanism is the convergence of public interest and business initiatives, on the one hand, the BOT mode enables the local government to expand the field of road sign public services without straining the public finance, on the other hand, BOT might be more effective in responding to the needs of urban business development.

Beginning in 2010, the contract for BOT crossroad guiding system in Dongguan city is ten years, which will be due in 2020 . It is interesting to discover that BOT road signs also exist in Xintang county, Zengcheng district of Guangzhou city, which is adjacent to the north of Dongguan city, but no presence of BOTs are found in the city proper of Guangzhou further west, nor they have any existence in Shenzhen city, which is another metropolis to the south of Dongguan city. Ever since their first establishment in the urban semiotic landscape in 2013, what dynamics and trends of public-private hybrid signs could be found? What can we learn from the evolution of BOT signs?

\subsection{Development of Interdiscursive Dialogicality}

A longitudinal survey was conducted to study different areas, which included three crossroads along the Guangshen Dadao running through the center of Xintang County, Guangzhou City and four crossroads along Qifeng Lu in the urban center of Dongguan City. Diachronic data ranging from the year 2014 through 2019 (some years' data are missing due to limited resources) are collected and inscriptions on each sign post are categorized into the fore-mentioned 4 types, A. public place names; B. PSA; C. paid-for place names and D. To-let (Self-Ad), which would supposedly reveal the dynamics between several key factors in the play.

As we can see the raw data from Table 1 and Table 2, all four types of inscription exist in Dongguan, but only three types save PSA are found in Xintang. By observing the diachronic trends from Line Graph 1 and Line Graph 2, we can draw comparisons behind the two regions which may shed light on the dynamics of BOT public-private hybrid signage. The followings are preliminary observations and comparisons from the data:

1) There seem to be an invisible hand that are maintaining the hierarchical order between different types of signage. Proportionally speaking, Xintang's data is clean-cut and generally stable over the observed period, with public signs being the most, paid-for place names come second and self-Ads last. The starting point of Dongguan's data is similar to that of Xintang, but went through dramatic changes. With the number of public signs dropping and paid-for places rising through 2014-2017, the two seemed to converge in 2018, and in 2019, they are trending in a way that the relative proportion of Public, Paid-for places and PSA is restored to that of 2014, with the exception of To-let self-Ads shot up to the second place.

This change and restoration might suggest the authority's guidance and intervention to maintain the appropriate outlook of BOT signs. 
Table 1: Diachronic Distribution of BOT Sign Inscriptions in Xintang County, Guangzhou City

\begin{tabular}{llll}
\hline Peak & 2016 & 2017 & 2019 \\
\hline Public & 84 & 88 & 80 \\
PSA & 0 & 0 & 0 \\
Paid-for places & 68 & 36 & 60 \\
To-let & 28 & 28 & 40 \\
Subtotal & 180 & 152 & 180 \\
\hline
\end{tabular}

Table 2: Diachronic Distribution of BOT Sign Inscriptions in Dongguan City Proper

\begin{tabular}{llllll}
\hline Peak & 2014 & 2016 & 2017 & 2018 & 2019 \\
\hline Public & 36 & 34 & 26 & 26 & 50 \\
PSA & 6 & 10 & 8 & 17 & 14 \\
Paid-for places & 22 & 50 & 55 & 30 & 36 \\
To-let & 6 & 10 & 8 & 24 & 40 \\
Subtotal & 70 & 104 & 97 & 97 & 140 \\
\hline
\end{tabular}

2) To-let self-Ads are rising, but with different associations. In Xintang, self-Ads increased between 2017-2019 is likely to be a response to the poor performance of paid-for places in as early as 2017, whereas in Dongguan, the significant rise of To-let ads seems to be synchronic to the drastic decline of paid-for place names in the same year of 2017, a commercial reaction more responsive than that of Xintang. And the self-Ads in Dongguan also hold an overtly strong presence, accounting for the second most of all sign types, reflecting the operator's eagerness to sell their Ad spaces on the road sign posts.

3) Unlike the prominence of public service message displayed on giant outdoor screens we have examined in Guangzhou previously, PSA has no presence in Xintang's BOT sign posts, and occupies only a marginal status on those in Dongguan. However, if we compare Dongguan's BOT road signs to those purely public road signs in Guangzhou city proper, there is more room for discussion as for what place would be better for conveying public service messages.

Line Graph 1: Diachronic trends of BOT sign inscriptions in Xintang county, Guangzhou city

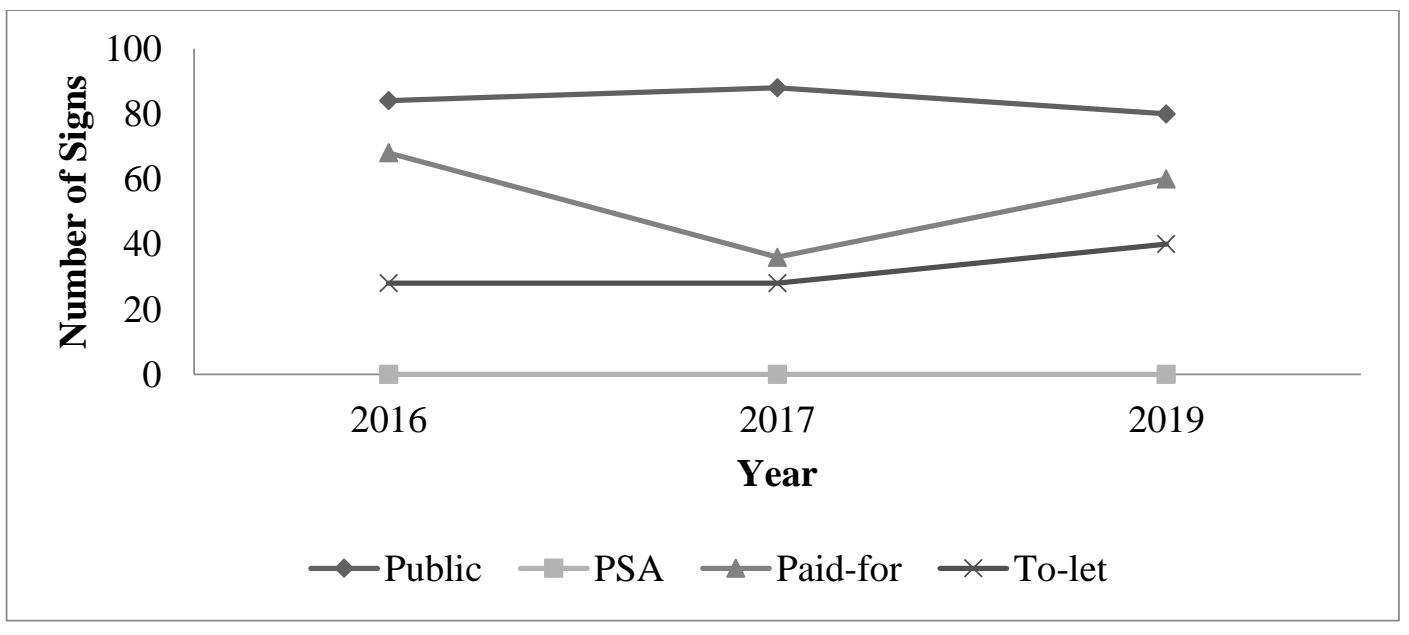


Line Graph 2: Diachronic trends of BOT sign inscriptions in Dongguan city proper

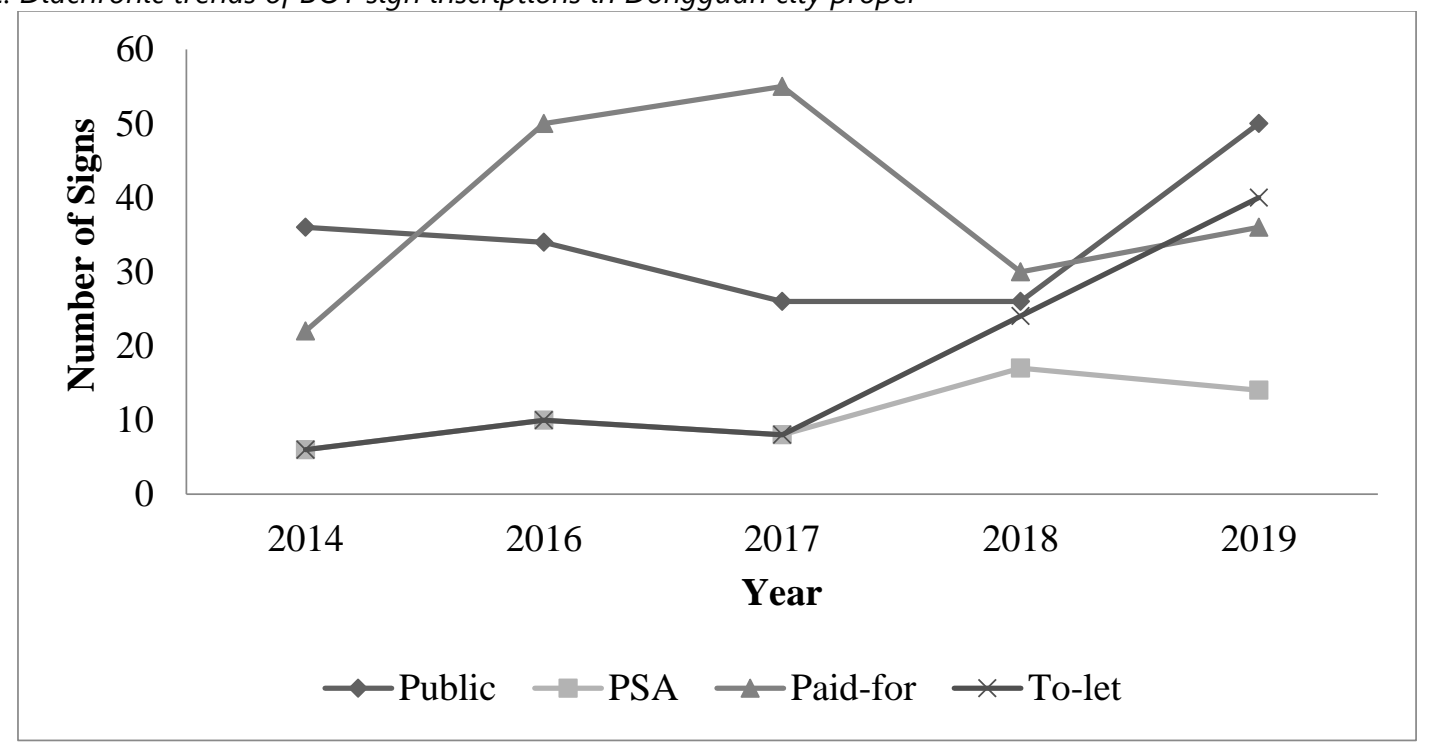

\subsection{Alleged Benefits of Public-Private Hybrid BOT Signage}

We have discussed briefly about the general situation and the past trends of BOT signage in Xintang and Dongguan, It is desirable to analyze their potential advantages and drawbacks in more detail. The following is a general examination of the alleged benefits by the BOT operator against the observed facts in the study.

Alleged benefits\#1: For the community, BOT signage expands the public sign service area. Mostly true, BOT signs in Dongguan city can be spotted more frequently than conventional public road signs in other cities in the Pearl River Delta region, even Guangzhou. It's worth noting that although Xintang county is only a town under the governance of Zengcheng District, the Zengcheng city proper has fewer road signs at major crossroads than Xintang County has, since Zengcheng city does not have BOTs in place.

Alleged benefits\#2: For the government, operating BOT signage lessens local government's fiscal burden. Perhaps true, relevant government documents DID NOT reveal anything about the financing situation regarding this matter, but judging from the fact that all signage related costs are to be borne by the BOT company, it can be expected that local government saves money on issues with signs.

Alleged benefits \#3: For the listed companies, provide precision guiding, credibility, customer care, lure potential clients and maintain brand image for your company. Partly wrong, but partly true. Since the BOT signs' four vectors are installed in a fixed crisscross position, the directional precision provided is very limited, let alone the so-called "credibility and customer care" in that respect. However, the information of the listed company on a BOT sign may really attract potential clients since it is being displayed in a crossroad where people are supposed to be abundant in numbers. In general analysis, the alleged benefits are mostly valid but not without any challenges, what's more problematic still is to review the BOT signs in a sociolinguistic perspective.

\subsection{Problems of Public-Private Hybrid BOT Signage}

The following is a general examination of the problems existing in the BOT signage.

\section{1) 5.6.1. Mismatched Indexicality}

Mismatched indexicality is the first problem concerning the BOT public-private hybrid signs. A road sign in the public crossroad is presumably providing people with guidance to the often nearby yet easily lost-in-direction venues and places of the general public's interest, it is usually sanctioned by the government and therefore supposed to be an authoritative statement about the local places as well as their directions, thus the inscriptions listed on a sign index geosemiotically note-worthy public places, which means a name on the sign carries certain weight or priority among "peers" in the eyes of the public. However, as it is observed on the many BOT signs, the plate size of public places such as hospitals and schools is often smaller than those of paid-for places, e.g. private firms, as well as those sign makers' self Ads, crippling the supposedly CORE code of public 
inscriptions in visual appearance, instead, the peripheral code of paid-for private business entities and sign maker Ads are more visible.

This core-peripheral code's mismatch in sign sizes reflects an abuse of the fundamental public function of a road sign post should serve, resulting a displaced indexicality of public places for road signs. It also means a road sign's marketization could be encroaching on the public interest to certain degree, which probably violates the original aspirations of Meiyu BOT company's slogan 'serve the city, community and commerce' per se.

\section{2) 5.6.2. Confusing Interdiscursive Dialogicality}

The issue of interdiscursive dialogicality arises when the quantity of information varies on different genres of signs, the followings are the rankings of signs in descending orders of discursive diversity and the information contain, A) paid-for signs: name, address, Tel \#, logo(in some cases), slogans(in some cases), ; B) To-let self-Ads: name, Tel \#, address(in some cases); C) public places: name, distances. D) Public Service Announcement: PSA itself only. In addition to the fact that sign sizes are in favor of the paid-for places and self-Ads, what exacerbates the incongruity is the imbalance of message provided on each type of signs, with those on the paid-for signs being the most abundant, followed by self-Ads and then to the public ones. There seems to be a different logic to the discursive construction between different signs, the discourses of public places tend to be more formal and conventional, and those of PSAs are like miniature versions of those big outdoor PSA billboards without scenic picture as the background, whereas private discourses, especially those on the paid-for places and sign makers self-Ads, are more "business card" like, providing essential business information, e.g. logos, addresses and telephone numbers, even slogans.

In summary, there are three types of distinctive discourses on a typical BOT sign post, conventional public sign discourse, PSA discourse and "business card" discourse; all operate independently within their respective signs, with few traces of influence from each other, in which case forming interdiscursive dialogicality, resulting in confusion to the readers.

\section{3) 5.6.3. Displaced Public Service Advertisements}

PSAs on a sign post could be bewildering or even redundant to pedestrians who want to find places. The rudimentary function of a typical sign post is to provide directions for nearby locations, with geospatial functions at the core, showing moral path is secondary. Therefore PSAs are usually not an expected element, where it is absent in Xintang's data. However, in Dongguan, the pattern of PSAs is more complex, they seem to be acting like stuffing or fillers for the sign posts that are less rich in either public or private information, PSAs fill up the gap between the reality and "what a sign post should look like", but in the urban center of Dongguan, where sign posts are abundant with all sorts of public and business signs, PSAs disappear in these cases.

Based on the observation, it is speculated that the PSA signs, though desirable by the government, may actually acquire a lower status than the signs of public places and private firms, and they are subject to removal as public and business needs arise, which means the PSAs have to give up their spaces for those public and paid-for elements in any moment. Generally speaking, putting PSAs on a crossroad sign post is probably not serving its function well but making unnecessary distractions for the viewers.

\section{4) 5.6.4. Incongruity of Sign Design}

Multimodal analysis also reveals incongruity in the signs' randomly chosen color scheme and layout design. In terms of the color choice of the BOT signs, it is predominantly yellowish fonts on pitch black sign board, which seems to be mimicking the color scheme on construction vehicles, despite not signaling danger and caution in our cases. This color scheme is highly visible in a distance, the BOT operator Meiyu even claimed it could be read clearly 60 meters away, even at night. However, one of the confusing arrangements is that one discourse may possess different hues of fonts, e.g. for one To-let self-Ad text content, which appear on three sign boards on the same surface of the post, their fonts would look greenish yellow, light yellow or bright yellow respectively. This diversifying color approach to the same discourse may cause distractions; viewer might mistake them as different contents.

Another issue is the layout design, there seems to be a uniform and consistent standard regulating the signs of public places, but only random layouts for the other genres. For example, a paid-for sign may or may not display a logo; the fonts in them could differ in sizes and shapes to fit the signboard area no matter how distorted the font may look and the hue of fonts could also be randomly rendered. The incongruity of sign appearance caused by random color scheme and layout design for non-public places discourse could cause confusion and distraction, which is potentially detrimental to fulfill its innate functions.

\section{Discussion}

In the previous analysis, we may gain an impression that the phenomenon of public-private dual discursive signage is complex and dynamic, yet public and private elements in the semiotic landscape are not irreconcilable. The key to answer the questions 
of the seemingly incongruous public-private coexistence on urban signage is by analyzing the ownership structure, operation modes and historic trends through diachronic geosemiotic observations.

In public-private (private-public) mixing signs, a shared ownership determines a mixed discourse, whereas for hybrid signs, which are usually of exclusive ownership, are more likely to have clear boundaries to delineate genres of discourses. Furthermore, the mode of operation will also have a crucial influence of what type of discourse will or will not be presented and how they look. For a business-oriented BOT mode, the dynamics between public and private discourses are not fixed, but rather subject to the local economic situation and commercial needs. Similar BOT signposts could even take on different appearance between various operators across regions.

Longitudinal observation is necessary to reveal the relationship between public and private elements on a sign at one time, and to see the patterns of dynamic changes and the unchanged, together with the trends in clearer detail. With a time span of 7 years, we can see that public-private mixing signs in Guangzhou could be staying for a long time, or be replaced by pure commercial signs, as long as the $3 \%$ bottom line of PSA presence is kept. For the same period, public-private hybrid signposts in Xintang and Dongguan have their location specific characteristics, though public, commercial and PSA elements might have experienced significant changes, different constituents on the hybrid signage in both places seem to be trending back to their original status as they were first put into place.

Although the public-private mixing or hybrid category discussed are not so "clean" in the past demarcation paradigms but it is a helpful and important complement to the system of semiotic landscape. As we have referred to in the beginning, relationship between public-private discourses is not rivalry, and dual discursive phenomena should not be simply dismissed as tokens of political intervention of business advertisement (probably for mixing billboards) or commodification of public services (probably for BOT roadsigns), because there are institutional, financial, commercial and operational forces interwoven, making dual discursive signs effective to different audience.

The mixing or hybrid signs' ultimate legitimacy may actually derive from whether they serve the society well enough, including both public and commercial entities. Therefore, the central argument for this paper is not only to add a new category in-between the existing public and private signage demarcation paradigm and chart its trajectory in recent years, but also to raise questions about the future for such a category, will they survive or not, either the answer be yes or no, we'd like to know how will it develop.

\section{Conclusion and Practical Implications}

In the previous analysis, we've seen cases of public and private discourses "mix" together on a screen on building façade, or they "fight" for dominance on BOT signs, with either party gained an upper hand for some time in the observed period. Despite the complex dynamics, we could argue that there are two fundamental rules towards an improved dual discursive semiotic landscape, one is the rule of shared space, and the other is the rule of harmonious presentation.

Result No.1: the shared of space is the basis for dual discourse signage's legitimacy, we all live in an environment full of all types of signage, each sign, either public or private or public-private mixing, existing within the linguistic landscape conglomerate is automatically entitled to a share of it. Therefore, sharing is an innate property of all sanctioned signs, which means it needs to be ensured seriously.

Result No.2: the harmonious presentation is for reaching the goal of serving the community, which is also to enact most signage's original purpose. In view of the previous study, we can put forward two guidelines for constructing a harmonious dual discourse signage, 1) For all mixing and hybrid signs, public and private elements should not interfere or obstruct each other or cause confusion, so it'd better to have boundaries. 2) For all mixing and hybrid signs, a hierarchical order should be set up for different discourses to establish a clearly hierarchical indexicality, therefore reduce confusion and distraction for viewers to a minimum.

Funding: This work was part of the results of the project Towards the Ecolinguistic Landscaping in Guangdong (grant number GD17WXZ33) sponsored by the 2017 Specialized Research Fund of Foreign Languages from the Guangdong Social Sciences "13th Five-Year Plan" planning projects, P.R.China.

Acknowledgments: The author declares that this research was individually completed.

Conflicts of Interest: The author declares no conflict of interest. No funder ever participated in any stage of creating this article. 


\section{References}

[1] Anonymous. (2013). Casting Doubts on Guangzhou's 'Most Astonishing' Advertising Complex. The Yangcheng Evening News. 2013-01-16, accessed 2020-08-20.

[2] Ben-Rafael, E.. Shohamy, E., M.H. \& Trumper-Hecht, N.(2006). Linguistic landscapes as symbolic construction of the public space: the case of Israel, in D. Gorter (Ed.) Linguistic Landscape: A New Approach to Multilingualism (pp. 7-30), Multilingual Matters.

[3] Blommaert, J. (2013). Ethnography, Superdiversity and Linguistic Landscapes: Chronicles of Complexity, Multilingual Matters.

[4] Cenoz, J. and Gorter, D. (2004). Linguistic landscapes and minority languages. Gorter, D. (ed.) 2006. Linguistic Landscapes: A New Approach to Multilingualism (pp. 67-80), Multilingual Matters.

[5] Coupland, N. (2010). Welsh Linguistic Landscapes 'From Above' and 'From Below'. Jaworski, A. and C. Thurlow. (Eds.) Semiotic Landscapes: Language, Image, Space (pp. 77-101), Continuum.

[6] Chmielewska, E. (2010). Semiosis Takes Place or Radical Uses of Quaint Theories. Jaworski, A. and C. Thurlow. (Eds.) Semiotic Landscapes: Language, Image, Space (pp. 274-291), Continuum.

[7] Dray, S. (2010). Ideological Struggles on Signage in Jamaica. Jaworski, A. and C. Thurlow. (Eds.) Semiotic Landscapes: Language, Image, Space (pp. 102-122), Continuum.

[8] Guangzhou Municipal Government. (2006/2010/2014/2018). Regulations on the outdoor advertising and signboards in Guangzhou, Guangzhou Municipality Office.

[9] Jaworski, A. and C. Thurlow. (Eds.) (2010). Semiotic Landscapes: Language, Image, Space, Continuum.

[10] Kallen, Jeffrey L. (2010). Changing Landscapes: Language, Space and Policy in the Dublin Linguistic Landscape. Jaworski, A. and C. Thurlow. (Eds.) Semiotic Landscapes: Language, Image, Space (pp. 41-58), Continuum.

[11] Landry, R. and Bourhis, R.Y. (1997). Linguistic landscape and ethnolinguisitc vitality: An empirical study. Journal of Language and Social Psychology, 16(1), 23-49.

[12] Li, Y. (2011). Linguistic Landscape Approach: A longitudinal Study about Beijing Road in Guangzhou. Overseas English, $181(11), 300-301$.

[13] Scollon, R. and Suzie Wong Scollon. (2003). Discourse in place: Language in the Material World, Routledge.

[14] Wu, Xili \& Zhan, J. (2017). The Multilingual Landscape of the African Street in Guangzhou City in the Context of Globalization. Foreign Language Research, 16(2), 6-11.

[15] Wu, Xili. (2017). A Critical Review of the Research of Multilingualism in the Linguistic Landscape. Journal of Guangzhou University (Social Science Edition), 16(8), 78-83. 